\title{
ALIMENTAÇÃO DE LARVAS DE JUNDIÁ (Rhamdia quelen), COM DIETAS ARTIFICIAIS
}

Rosamari Piaia, Oclécio Uliana, Jorge Filipetto e João Radünz Neto

Departamento de Zootecnia - CCR

UFSM - Santa Maria, RS

\section{RESUMO}

O trabalho teve como objetivo avaliar o efeito de diferentes fontes protéicas sobre o desempenho de larvas de Rhamdia quelen durante o período inicial de 21 dias. Utilizou-se cinco tratamentos e três repetições. Grupos de 200 larvas foram estocadas em condições controladas de cultivo, utilizando-se um sistema de criação com reutilização de água, termoregulada. O alimento foi oferecido a cada 2 horas. Os tratamentos testados foram: T1 (gema de ovo cozido, farinha de peixe); T2 (levedura, fígado bovino cru); T3 (farelo de soja; fígado bovino cru); T4 (farelo de soja, arroz e milho) e T5 (farinha de peixe, carne e farelos de soja e arroz). Os tratamentos T2 e T4 apresentaram maiores taxas de sobrevivência do que os tratamentos T1, T3 e T5, não havendo diferença significativa entre T2 e T4 os quais diferiram dos demais tratamentos. O T1 apresentou maior média de comprimento aos 21 dias do que T2 e este teve melhor desempenho do que o T3, T4 e T5 os quais não tiveram diferença entre si. Constatou-se que o tratamento composto por levedura e fígado é mais eficaz sobre o desempenho inicial de larvas de jundiá, e apresenta-se como boa alternativa para ser usada em rações.

Palavras-chave: farelo de soja, fígado, levedura, nutrição. 


\section{SUMMARY}

The study had the purpose of evaluating the effects of different protean sources in the performance of Rhamdia quelen larvae during 21 days. Five treatments and three repetition were utilized. The experimental foods utilized were: T1 (fish meal, hard boiled yolk eggs); T2 (yeast, crud bovine liver); T3 (soybean's meal, bovine liver); T4 (corn's meal, soybean meal and rice); T5 (fish meal and meat, soybean and rice). Groups of 200 larvae were maintained in controlled conditions of culture, utilizing a water reuse system, termoregulated. The food was offered every 2 hours. The T2 and T4 treatments showed higher rates of survival than T1, T3, and T5. No difference was found between T2 and T4, but both were different from T1, T3, and T5. T1 showed higher length mean in 21 days than T2, but T2 had better performance than T3, T4 and T5. No difference was found among T3, T4, and T5. The treatment with yeast and liver was more efficient in the inicial performance of the larvae and it showed to be a good alternative to be utilized in future studies.

Key words: liver, nutrition, soybean meal, yeast.

\section{INTRODUÇÃO}

A larvicultura para a produção de alevinos com tamanho adequado para o abastecimento das criações na fase de engorda, constitui um dos sérios obstáculos ao desenvolvimento da criação. Um dos grandes problemas com que se defronta a piscicultura é a sobrevivência da larva em seus primeiros dias de vida. A alimentação da larva, logo após absorver o saco vitelino, corresponde a um ponto de suma importância devido à elevada mortalidade que a falta de alimento pode provocar.

No Brasil poucos trabalhos têm sido realizados sobre as exigências nutritivas e o comportamento alimentar de larvas e alevinos do jundiá. Estudos preliminares relativos à nutrição foram realizados na 
Argentina por LUCHINI \& SALAS (1984), no Uruguai por VARELA et al. (1983) e no Brasil por SANTOS et al. (1988), com larvicultura e alevinagem do bagre sul-americano Rhamdia sapo. Ccontudo, nada de definitivo existe sobre o alimento mais adequado, principalmente na fase inicial de desenvolvimento das larvas.

As necessidades nutricionais de peixes nos estágios iniciais são muito pouco conhecidas em comparação àquelas de juvenis e adultos. Para algumas espécies de água doce as técnicas de criação de larvas vem sendo estudadas. Este fato abre a perspectiva do uso de dietas artificiais para a primeira alimentação sem o uso de qualquer forma de alimento vivo (KAUSHIK, 1988).

O presente trabalho foi elaborado com a finalidade de avaliar o uso de diferentes fontes protéicas sobre o crescimento e sobrevivência de larvas do jundiá Rhamdia quelen nos primeiros dias de vida, colaborando com o desenvolvimento da piscicultura em uma de suas etapas mais críticas, a larvicultura.

\section{MATERIAIS E MÉTODOS}

O experimento foi realizado no Setor de Piscicultura, localizado no Departamento de Zootecnia, Centro de Ciências Rurais da Universidade Federal de Santa Maria, RS, no período de 20 de março a 11 de abril de 1995.

O experimento foi realizado num sistema de re-circulação de água, termorregulada, acoplado a um biofiltro descrito por CHARLON \& BERGOT (1984) (Figura 1). Este sistema possui 16 unidades de criação feitas em fibra de vidro. Cada unidade é constituída de duas bacias, uma externa $(38 \times 38 \times 15 \mathrm{~cm})$ e uma interna $(33 \times 33 \times 13 \mathrm{~cm})$, provida de tela com capacidade para 8 । de água. Estes reservatórios foram dotados de abastecimento d'água individual, com uma vazão de $0,2 \mathrm{l} / \mathrm{min}$ na primeira 
semana, aumentando-se gradativamente até $0,6 \mathrm{l} / \mathrm{min}$ na terceira semana experimental. A água, oriunda de poço artesiano, foi mantida em caixa d'água a uma temperatura de $23^{\circ} \mathrm{C}$. $\mathrm{O}$ sistema de re-circulação da água possibilitava uma oxigenação constante.

As larvas de jundiá Rhamdia quelen utilizadas foram obtidas no Setor de Piscicultura, através de desova induzida. Após a absorção do saco vitelino, com idade de cinco dias, foram contadas de $10 \mathrm{em} 10 \mathrm{e}$ ocuparam uma lotação de 200 larvas por unidade experimental.

Foram testados os valores nutricionais de cinco tratamentos, com fontes protéicas de origem vegetal e animal descritos a seguir: T1: farinha de peixe e gema de ovo cozido (RADÜNZ NETO, 1981); T2: levedura e fígado bovino cru (CHARLON \& BERGOT, 1984) e T5: farinhas de peixe e carne, farelos de soja e arroz (WOYNAROVICH, 1986), sendo que T3: farelo de soja e fígado bovino cru e T4: farelos de soja, arroz e milho, foram formulados através do programa computadorizado BRILL para cálculo de rações (Tabela 1).

Para a preparação das rações experimentais (T2 a T5), os ingredientes foram inicialmente triturados em moinho da marca TECNAL, para grãos secos, peneirados de modo a se obter uma granulometria $<75 \mu$. Após a pesagem e homogeneização completa dos ingredientes, aproximadamente $30 \%$ de água destilada foi adicionada com a finalidade de obter a consistência desejada. A ração foi passada em máquina de moer carne e em seguida seca em estufa com ar forçado a $40^{\circ} \mathrm{C}$ por 48 horas. Após a secagem a ração foi triturada e peneirada novamente, e recuperadas partículas de 125 a $300 \mu$ para a $1^{\text {a }}$ semana e 300 a $710 \mu$ para $2^{a}$ e $3^{\text {a }}$ semanas experimentais. Para o T1 os ingredientes foram somente homogeneizados, e a ração foi oferecida sob forma de pasta.

O premix vitamínico utilizado era pré-fabricado, formulado para aves. Os valores de minerais seguiram requerimentos para 0 bagre americano (Ictalurus punctatus) segundo HEPHER (1990).

$\mathrm{O}$ alimento foi fornecido à vontade, diariamente, a cada duas horas, formando uma camada flutuante sobre a superfície d'água. Foi 122 Rev. Ciência e Natura, Santa Maria, 19: 119 - 131 , 1997 
utilizado um fotoperíodo de 12 horas através do uso de lâmpadas fluorescentes.

Diariamente foi feita a limpeza das caixas e contagem dos peixes mortos. A transferência das larvas foi realizada com água para as bacias limpas, através da inclinação das mesmas, possibilitando assim que o material orgânico ficasse retido nas paredes das bacias.

Semanalmente foram retiradas amostras de 10 peixes de cada unidade experimental (sem retorno) para realização das medidas de comprimento total (CT) e comprimento padrão (CP). Estas medidas foram realizadas com auxílio de lupa e papel milimetrado.

Ao final do experimento foi realizada a contagem das larvas sobreviventes em cada repetição e tomado o peso total das mesmas, com auxílio de balança de precisão. O peso médio individual foi obtido através da divisão das médias de peso total pelo número de sobreviventes.

A taxa de sobrevivência foi calculada considerando-se os sobreviventes acrescidos das amostras de peixes vivos retiradas a cada sete dias para realizar as medidas de CT e CP.

Os parâmetros analisados foram: taxa de sobrevivência, comprimento total e padrão, peso médio individual e produto peso versus sobrevivência.

O delineamento experimental foi o inteiramente casualizado com cinco tratamentos e três repetições. Os dados foram submetidos à análise de variância e teste de Tuckey para comparação entre as médias a um nível de significância de $5 \%$.

\section{RESULTADOS E DISCUSSÃO}

A avaliação da taxa de sobrevivência dos peixes indica que o número de larvas sobreviventes aos 21 dias foi maior nos tratamentos T2 e T4 (Tabela 2), com um número reduzido de peixes desaparecidos. A maior incidência de desaparecidos nos demais tratamentos poderá ser devida à 
dificuldade de identificação de larvas mortas durante a primeira semana de vida, as quais misturam-se ao excesso de alimento distribuído ao longo do dia que depositava-se no fundo das bacias. Outra possibilidade é a ocorrência de canibalismo, constatado visualmente algumas vezes no tratamento T1.

O tratamento T2 com melhor eficiência em sobrevivência $(90,80 \%)$ demonstra uma boa combinação entre os ingredientes. A levedura seca de destilaria alcoólica (Saccharomyces cerevisae) se apresenta como boa fonte alimentar apresentando boa atratividade e palatabilidade (PEZZATO, 1995) e o fígado bovino tem seu efeito positivo. Estes dados concordam com os resultados de ALAMI-DURANTE et al. (1991) obtendo 95\% de sobrevivência em larvas de Cyprinus carpio para o mesmo tratamento.

Os resultados de crescimento expressos em comprimento total e comprimento padrão estão indicados na Tabela 4. Ao analisarmos individualmente o comprimento total constata-se uma diferença entre os tratamentos T1 e T2 e os demais já a partir da primeira semana de idade. A diferença entre T1 e T2 só ocorreu aos 21 dias quando as larvas daquele atingem $18,20 \mathrm{~mm}$ e deste $15,20 \mathrm{~mm}$. As larvas dos demais tratamentos apresentaram menor crescimento, não havendo diferença significativa entre eles, com exceção do T5 aos 14 dias.

Os tratamentos contendo farelo de soja apresentaram baixo crescimento. Isto pode ser devido a fatores anti-nutricionais encontrados no farelo de soja. Estas substâncias inibem a ação da tripsina e da eripsina, necessárias para a digestão da proteína, interferindo na absorção de aminoácidos sulfurados e no metabolismo da vitamina A (ANDRIGUETTO, 1983). Diferentes fatores anti-nutricionais encontrados no farelo de soja, tais como: inibidores de protease, lectinas, proteínas antigênicas, compostos fenólicos e fitatos, afetam a digestão e absorção dos nutrientes nos peixes segundo KAUSHIK et al. (1995). Também uma possível deficiência em aminoácidos sulfurados na soja, como a metionina (ESCAFFRE \& KAUSHIK, 1995), ou pouca atrato-palatabilidade (PEZZATO, 1995) poderiam resultar 
em baixo crescimento. Segundo BERGOT (1986) não somente a possível deficiência em enzimas digestivas, em particular as proteolíticas, mas uma deficiência na suplementação nutricional em aminoácidos essenciais, vitaminas e minerais resulta em menor desempenho durante a primeira fase de vida das larvas de peixes.

Os dados de peso médio individual dos peixes aos 21 dias apresentaram diferença significativa entre os tratamentos sendo T1 o melhor seguido de T2. Entre os demais tratamentos não houve diferença significativa para os pesos médios individuais que foram extremamente baixos (Tabela 3). O melhor resultado em ganho de peso apresentado pelo T1 pode seer devido ao menor número de larvas sobreviventes uma vez que ocorre uma maior disponibilidade de alimento, outra possibilidade seria a rápida desagregação do alimento na água, beneficiando as larvas que primeiro atacavam o alimento.

Considerando-se o produto peso versus sobrevivência, com a finalidade de avaliar a biomassa final de peixes aos 21 dias encontrou-se o melhor índice para o tratamento T2 $(30,31)$ que diferiu estatisticamente dos demais (Tabela 3). Os tratamentos T3, T4 e T5 apresentaram resultados de peso versus sobrevivência extremamente baixos, mesmos com o alto índice de sobrevivência do T4.

\section{CONCLUSÕES}

Os resultados nos mostram que a mistura levedura mais fígado bovino apresenta-se como boa alternativa a ser utilizada na primeira fase de vida do jundiá Rhamdia quelen; porém mais análise deverá ser realizada no sentido de determinar níveis ótimos de incorporação deste alimento. Estudos futuros devem ser realizados para avaliar níveis de aminoácidos, teores de lipídios, bem como vitaminas e minerais presentes na dieta a ser fornecida na criação de larvas desta espécie. 


\section{REFERÊNCIAS BIBLIOGRÁFICAS}

ALAMI-DURANTE, H., CHARLON, N., BERGOT, P. Supplementation of artificial diets for common carp (Cyprinus carpio) larvae. Aquaculture, p. 167-175, 1991.

ANDRIGUETTO, J.N. Nutrição animal. 2 a ed. São Paulo: Nobel, 1983. v. 1, $395 \mathrm{p}$.

BERGOT, P. Elevage larvaire de la carpe commune (Cyprinus carpio L.): alimentation artificielle. Aquaculture of Cyprinides, INRA, Paris, p. 227-233, 1986.

CASTAGNOLLI, N. Fundamentos da nutrição de peixes. Piracicaba: Livroceres, 1979. 107 p.

CHARLON, N., BERGOT, P. Rearing system for feeding fish lavae on dry diets. Trial with carp (Cyprinus carpio, L.) larvae. Aquaculture, n. 41, p. 1-9, 1984.

ESCAFFRE, A.M., KAUSHIK, S.J. Survival and growth of first-fee-ding Coomon carp larvae fed artificial diets containing soybean protein concentrate. Aquaculture, n. 129, p. 251-259, 1995.

HEPHER, B. Nutrition of pond fishs. Inglaterra: Cambridge Univ Press, 1990. $388 \mathrm{p}$.

KAUSHIK, S.J. Major constraints and recent advances in the field of nutrition and feeding of fish larvae. 1988. Sept 19-23. Seminar on "Aquacultura Marina". $14 \mathrm{p}$.

KAUSHIK, S.J., GRAVEDI, J.P., LALLES, J.P. Partial or total replacement of fish meal by soybean protein on growth, protein utilization, potential estrogenic or antigenic effects, cholesterolemia and flesh quality in rainbow trout, Oncorhynchus mykiss. Aquaculture, n. 133, p. $257-$ 274, 1995.

LUCHINI, L., SALAS, T. Preliminary data on larval survival of south American catfish, Rhamdia sapo. Aquaculture, n. 42, p. 175-177, 1984. 
PEZZATO, L.E. Alimentos convencionais e não convencionais dispo-níveis para a indústria de nutrição de peixes no Brasil. In: SIMPÓSIO INTERNACIONAL SOBRE NUTRIÇÃO DE PEIXES E CRUSTÁCEOS, 1995, Campos do Jordão. Anais... CBNA, Campos do Jordão, 1995, 126 p. p. 32-52.

RADÜNZ NETO, J. Desenvolvimento de técnicas de reprodução e manejo de larvas e alevinos de jundiá - Rhamdia quelen. Dissertação (Mestrado em Zootecnia) Universidade Federal de Santa Maria (1981). 77 p. Santa Maria - RS.

SANTOS, A.B., CHWA, E.Q., THOMPSON, D.M. Produção e criação de alevinos de Rhamdia sapo Valenciennes. In: VI SIMPÓSIO LATINOAMERICANO E V SIMPÓSIO DE AQÜICULTURA, 1988, Florianópolis, SC. Anais... Florianópolis, 1988, p. 615-620.

VARELA, Z., FABIANO, G., FISCHER, K. Cria de larvas de bagre negro (Rhamdia sapo, Valenciennes) en el laboratorio. Resumenes. Associación Ciencias Naturales, INSN, Montivedeo. Uruguai, n. 3, p. 117-118, 1983.

WOYNAROVICH, Tambaqui e pirapitinga propagação artificial e criação de alevinos, CODEVASF, 1986, 67 p. Brasília. 
TABELA 1 - Composição das dietas experimentais utilizadas na alimentação de larvas do jundiá Rhamdia quelen (em \%).

\begin{tabular}{llllll}
\hline \multicolumn{1}{c}{ INGREDIENTES } & \multicolumn{5}{c}{ TRATAMENTOS } \\
\hline & T1 & T2 & T3 & T4 & T5 \\
\hline Gema de ovo cozida & 49,25 & - & - & - & - \\
Farinha de peixe & 49,25 & - & - & - & 24,70 \\
Levedura de destilaria & - & 50,00 & - & - & - \\
Fígado bovino (peso seco) & - & 35,00 & 35,00 & - & - \\
Farelo de soja tostado & - & - & 50,00 & 57,50 & 24,50 \\
Farelo de arroz desengordurado & - & 13,50 & 13,50 & 12,00 & - \\
Óleo vegetal (soja) & - & - & - & 16,00 & - \\
Farelo de milho & - & - & - & 6,00 & 24,50 \\
Farinha de carne & - & - & - & - & 24,70 \\
Fosfato bicálcico** & - & - & - & 7,00 & - \\
Premix vitamínico* & 1,50 & 1,50 & 1,50 & 1,50 & 1,50 \\
\hline
\end{tabular}

* Composição da mistura vitamínica, segundo o fabricante (Companhia Minuano de Alimentos) - Níveis/kg do produto: Vit. $\mathrm{A}=$ $5.500 .000 \mathrm{UI}$, Vit. $\mathrm{D}_{3}=1.500 .000 \mathrm{UI}$, Vit. $E=12.500 \mathrm{mg}$, Vit $\mathrm{K}_{3}=1.750 \mathrm{mg}$, Vit $B_{1}=1500 \mathrm{mg}$, Vit $B_{2}=3.000 \mathrm{mg}$, Vit $B_{6}=1750 \mathrm{mg}$, Vit. $B_{12}=7000 \mathrm{mcg}$, cido fólico $=500 \mathrm{mg}$, ácido pantotênico $=5.000 \mathrm{mg}$, ácido nicotínico $=17.500$ $\mathrm{mg}$, Biotina $=75 \mathrm{mg}$, Cloreto de colina $=125.000 \mathrm{mg}$, DL-Metionina $=$ $300.000 \mathrm{mg}$ e Antioxidante $=7.500 \mathrm{mg}$.

** Produto adicionado para permitir relação $\mathrm{Ca} P \mathrm{P}$ igual a existente nos demais tratamentos. 
TABELA 2 - Dados de mortalidade, número de larvas desaparecidas e número total de sobreviventes no final do experimento.

\begin{tabular}{|c|c|c|c|c|c|}
\hline TRATAMENTOS & $\begin{array}{c}\text { REPETIÇÃ } \\
0\end{array}$ & $\begin{array}{l}\text { AMOSTRA } \\
\text { RETIRADA }\end{array}$ & $\begin{array}{c}\text { № DE } \\
\text { MORTOS }\end{array}$ & $\begin{array}{c}\text { № DESA- } \\
\text { PARECIDOS }\end{array}$ & $\begin{array}{l}\text { SOBREVI- } \\
\text { VENTES }\end{array}$ \\
\hline & 1 & 30 & 57 & 26 & 87 \\
\hline \multirow[t]{3}{*}{ T1 } & 2 & 30 & 44 & 56 & 70 \\
\hline & 3 & 30 & 64 & 27 & 79 \\
\hline & 1 & 30 & 19 & 0 & 151 \\
\hline \multirow[t]{3}{*}{ T2 } & 2 & 30 & 17 & 1 & 152 \\
\hline & 3 & 30 & 16 & 2 & 152 \\
\hline & 1 & 30 & 54 & 35 & 81 \\
\hline \multirow[t]{3}{*}{ T3 } & 2 & 30 & 57 & 22 & 91 \\
\hline & 3 & 30 & 44 & 32 & 94 \\
\hline & 1 & 30 & 8 & 17 & 145 \\
\hline \multirow[t]{3}{*}{ T4 } & 2 & 30 & 10 & 9 & 151 \\
\hline & 3 & 30 & 14 & 6 & 150 \\
\hline & 1 & 30 & 87 & 53 & 30 \\
\hline \multirow[t]{2}{*}{ T5 } & 2 & 30 & 106 & 39 & 25 \\
\hline & 3 & 30 & 101 & 40 & 29 \\
\hline
\end{tabular}


TABELA 3 - Dados médios referentes à sobrevivência (\%), peso médio individual (mg) e produto peso versus sobrevivência das larvas de jundiá (Rhamdia quelen), aos 21 dias.

\begin{tabular}{cccc}
\hline \hline TRATAMENTOS & $\begin{array}{c}\text { SOBREVIVÊNCIA } \\
(\%)\end{array}$ & $\begin{array}{c}\text { PESO } \\
(\mathrm{mg})\end{array}$ & $\begin{array}{c}\text { PESO } \mathbf{x} \\
\text { SOBREVIVÊNCIA }\end{array}$ \\
\hline T1 & $54,33 \mathbf{b}$ & $45,05 \mathbf{a}$ & $24,40 \mathbf{b}$ \\
T2 & $90,80 \mathbf{a}$ & $33,38 \mathbf{b}$ & $30,31 \mathbf{a}$ \\
T3 & $59,30 \mathbf{b}$ & $5,56 \mathbf{c}$ & $3,29 \mathbf{c}$ \\
T4 & $89,30 \mathbf{a}$ & $5,35 \mathbf{c}$ & $4,76 \mathbf{c}$ \\
T5 & $29,00 \mathbf{c}$ & $5,34 \mathbf{c}$ & $1,55 \mathbf{d}$ \\
\hline
\end{tabular}

a,b,c,d Valores com mesma letra, na coluna, não apresentam diferença significativa pelo teste de Tuckey ( $P$ 0,05).

TABELA 4 - Dados médios $(\mathrm{mm})$ de comprimento total $(\mathrm{Ct})$ e comprimento padrão (Cp) das larvas de jundiá (Rhamdia quelen).

\begin{tabular}{|c|c|c|c|c|c|c|c|c|c|c|}
\hline \multirow{2}{*}{ DIA } & \multicolumn{2}{|c|}{ T1 } & \multicolumn{2}{|c|}{ T2 } & \multicolumn{2}{|c|}{ T3 } & \multicolumn{2}{|c|}{ T4 } & \multicolumn{2}{|c|}{ T5 } \\
\hline & $\mathrm{Cp}$ & $\mathrm{Ct}$ & $\mathrm{Cp}$ & $\mathrm{Ct}$ & $\mathrm{Cp}$ & $\mathrm{Ct}$ & $\mathrm{Cp}$ & $\mathrm{Ct}$ & $\mathrm{Cp}$ & $\mathrm{Ct}$ \\
\hline 0 & $6,2 a$ & $7,0 \mathrm{a}$ & $6,2 a$ & $7,0 a$ & $6,2 a$ & $7,0 a$ & $6,2 a$ & $7,0 a$ & $6,2 a$ & $7,0 \mathrm{~b}$ \\
\hline 7 & $9,5 a$ & $11,0 \mathrm{a}$ & $10,0 a$ & $10,7 a$ & $7,5 \mathrm{~b}$ & $8,3 b$ & $6,8 b$ & $7,6 \mathrm{~b}$ & $7,1 \mathrm{~b}$ & $8,0 \mathrm{~b}$ \\
\hline 14 & $11,7 a$ & $13,5 a$ & $11,6 a$ & $13,6 a$ & $8,3 b$ & $9,6 b$ & $8,2 b$ & $9,4 b$ & $7,5 b$ & $8,4 b$ \\
\hline 21 & $15,5 a$ & $18,2 a$ & $13,1 b$ & $15,2 b$ & $9,3 c$ & $10,4 c$ & $9,1 \mathrm{c}$ & $10,2 \mathrm{c}$ & $8,4 c$ & $9,4 c$ \\
\hline
\end{tabular}

a,b,c Valores com mesma letra, na linha, não apresentam diferença significativa pelo teste de Tuckey $(P \geq 0,05)$. 
FIGURA 1 - Biofiltro descrito por CHARLON \& BERGOT (1984).

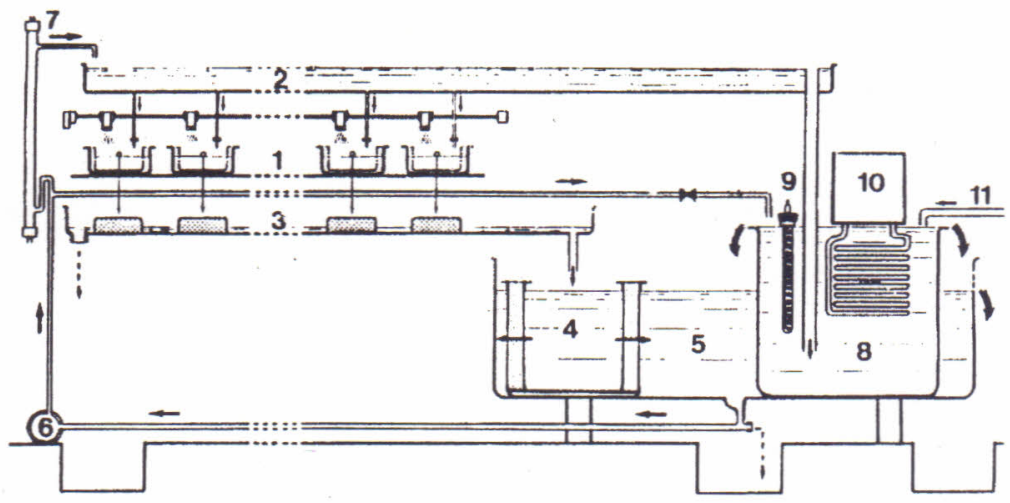

1 - Série de bacias de criação

2 - Calha superior de distribuição de água

3 - Calha inferior de recuperação de água

4 - Filtro biológico

5 - Reserva d'água

6 - Bomba

7 - Tubo ultra-violeta

8 - Bacia de termorregulação

9 - Resistência elétrica

10 - Grupo refrigerante

11 - Entrada d'água externa

Direção de circulação d'água

Dreno 
132 Rev. Ciência e Natura, Santa Maria, 19: 119 - 131 , 1997 